\title{
Epstein-Barr Virus-Negative Classical Hodgkin's Lymphoma in a Patient with T-Cell Prolymphocytic Leukemia Treated with Fludarabine
}

\author{
Takahiro Tsuji, ${ }^{1)}$ Hiroshi Yamasaki, ${ }^{1)}$ Nobuyuki Arima, ${ }^{2)}$ Daisuke Niino, ${ }^{3)}$ \\ Koichi Ohshima, ${ }^{3)}$ and Hiroyuki Tsuda ${ }^{1)}$
}

Keywords: T-cell prolymphocytic leukemia, Hodgkin's lymphoma, fludarabine

\section{TO THE EDITOR}

T-cell prolymphocytic leukemia (T-PLL) is a rare T-cell neoplasm characterized by the proliferation of small to medium-sized prolymphocytes with a mature post-thymic Tcell phenotype involving the peripheral blood, bone marrow, lymph nodes, liver, spleen, and skin. ${ }^{1}$ T-PLL is typically an aggressive disease. Moreover, the disease is usually resistant to conventional chemotherapy (alkylating agents or combinations such as cyclophosphamide/doxorubicin/vincristine/prednisolone), and is associated with a poor prognosis. ${ }^{1}$ The nucleoside analogue fludarabine, which is effective in treating B-cell chronic lymphocytic leukemia (CLL), is also effective in T-PLL. ${ }^{2,3}$ However, fludarabine can cause severe T-cell lymphopenia as a major side effect. ${ }^{4}$ Classical Hodgkin's lymphoma (CHL) is characterized by the presence of ReedSternberg cells and an extensive inflammatory infiltrate. Immunodeficiency status, such as autoimmune disease, use of immunomodulatory drugs, human immunodeficiency virus (HIV), primary immune disorders, and post-transplantation, increases the risk of CHL. ${ }^{5}$ CHL has been described in patients treated with fludarabine, and it is suggested that fludarabine-induced immunosuppression contributes to the development of CHL.5 Secondary development of CHL after treatment with fludarabine has been described in B-CLL or low-grade B-cell lymphoma patients. However, the devel-

\footnotetext{
Received : October 24, 2011

Revised : January 24, 2012

Accepted : February 28, 2012

${ }^{1)}$ Department of Hematology and Oncology, Kumamoto City Hospital, Kumamoto, Japan

2) Department of Clinical Pathology, Kumamoto City Hospital, Kumamoto, Japan

${ }^{3)}$ Department of Pathology, Kurume University School of Medicine, Kurume, Japan

Address correspondence and reprint requests to: Takahiro Tsuji, Division of Hematology and Oncology, Kumamoto City Hospital, Kotoh 1-1-60, Kumamoto 8628505, Japan. E-mail : tsuji.takahiro@city.kumamoto.lg.jp
}

opment of CHL in the background of T-PLL has not been reported previously. We present a patient with T-PLL who developed CHL after treatment with fludarabine.

In February 2002, a 57-year-old Japanese woman was admitted to our hospital, presenting with leukocytosis and skin eruption. Her hematologic values were as follows : hemoglobin concentration, $12.9 \mathrm{~g} / \mathrm{dL}$; white blood cell count, $10.3 \times 10^{9} / \mathrm{L}$; with $3.5 \%$ band neutrophils, $23.5 \%$ segmented neutrophils, $3.0 \%$ monocytes, $6.0 \%$ eosinophils, and $61.8 \%$ lymphocytes, and the platelet count was $256 \times 10^{9} / \mathrm{L}$. Morphologically, these peripheral blood lymphocytes were small to medium-sized cells with non-granular basophilic cytoplasm, and round or oval nuclei (Fig. 1). Immunophenotyping of the surface molecules of these lymphocytes by flow cytometry revealed the following phenotype : $\mathrm{CD}_{2}^{+}$, $\mathrm{CD}^{+}, \mathrm{CD}^{-}, \mathrm{CD}^{+}, \mathrm{CD}^{+/-}, \mathrm{CD}^{+}, \mathrm{CD} 25^{-}$. Viral tests for hepatitis $\mathrm{B}$ surface antigen, hepatitis $\mathrm{C}$ virus antibody, and human T-cell leukemia virus type 1 antibody were negative. Southern blot analysis of peripheral lymphocytes showed rearrangements of the T-cell receptor gene $\mathrm{C} \beta 1$ (TCRC $\beta 1$ ) re-

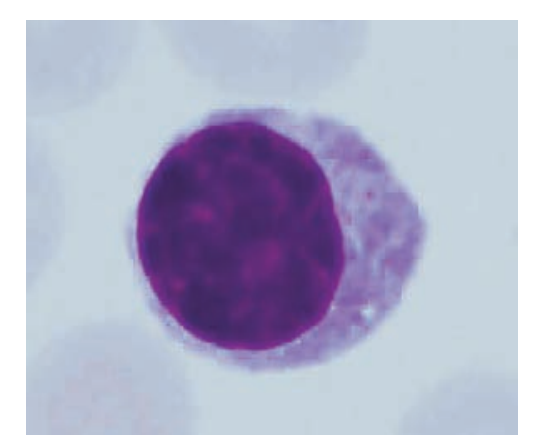

Fig. 1. Peripheral blood smear taken at the diagnosis of T-PLL. Atypical lymphocytes with non-granular basophilic cytoplasm, and round or oval nuclei. Wright-Giemsa stain, $\times 400$. 
A

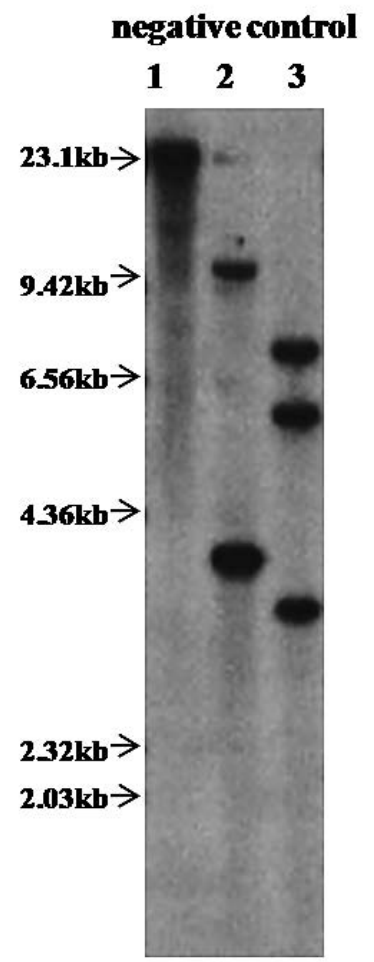

patient
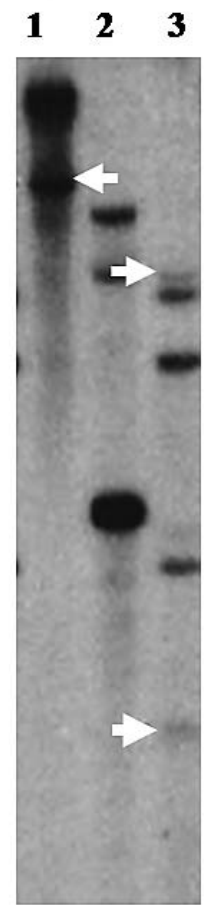

B

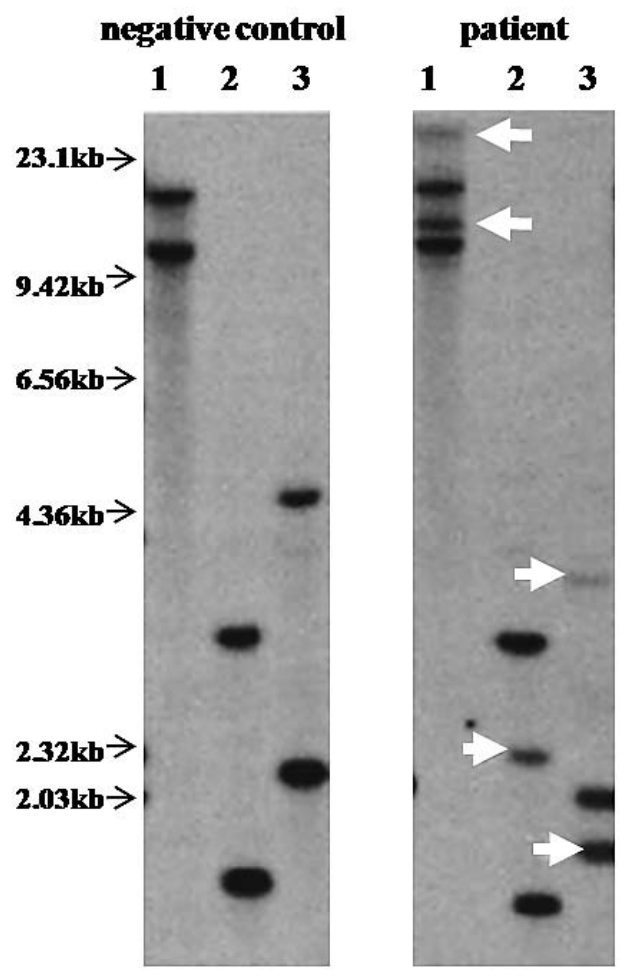

Fig. 2. Southern blot analysis of lymphocytes from the present patient $(2 A$, TCRC $\beta 1 ; 2 B$, TCR $\gamma$ ). DNA was digested with EcoRI (lane 1), BamHI (lane 2), and HindIII (lane 3). Rearrangements of the TCRC $\beta 1$ gene were detected in lanes 1 and 3 (arrows). Rearrangements of the $T C R \gamma$ gene were detected in lanes 1, 2, and 3 (arrows).

gion, and also TCR $\gamma$ region (Fig. 2). Thus, a diagnosis of TPLL was made. A skin biopsy specimen showed perivascular lymphocytic infiltration in the papillary dermis to subcutis. Immunohistochemically, the atypical lymphocytes were positive for CD3 and CD8, and negative for CD4. Skin eruption was diagnosed as the invasion of T-PLL cells. She received chemotherapy consisting of fludarabine $\left(25 \mathrm{mg} / \mathrm{m}^{2} /\right.$ day for 5 days). After two courses of chemotherapy, atypical lymphocytes were decreased and skin eruption disappeared.

In September 2009, the patient visited our hospital because of chest discomfort and skin eruption. Computed tomography $(\mathrm{CT})$ identified lymph node swelling at the right pulmonary hilar region and mediastinum (Fig. 3A). Wholebody 2-[18F] fluoro-2-deoxy-D-glucose positron emission tomography combined with computed tomography (FDGPET/CT) demonstrated abnormal uptakes in the pulmonary hilar lymph nodes, mediastinal lymph nodes, supraclavicular, and mesenteric lymph nodes (Fig. 3C). The peripheral lymphocyte count was not increased, and the level of lactate dehydrogenase was in the normal range. Southern blot analysis of peripheral lymphocytes indicated no rearrangement of the TCRC $\beta 1$ region and TCR $\gamma$ region. Soluble interleukin-2 receptor (sIL-2R) concentration was elevated $(1,087 \mathrm{U} / \mathrm{mL})$, while the levels of carcinoembryonic antigen (CEA), cytokeratin 19 fragment antigen (CYFRA), and progastrin-releasing peptide (ProGRP) were within normal ranges. Bronchoscopic biopsy specimens showed an infiltration of mature small lymphocytes with minimal nuclear abnormalities. They had a $\mathrm{CD}^{+}$and $\mathrm{CD} 8^{+}$suppressor/cytotoxic phenotype. We considered that T-PLL had been exacerbated. She received chemotherapy consisting of fludarabine $\left(25 \mathrm{mg} / \mathrm{m}^{2} /\right.$ day for 3 days $)$. After two courses of chemotherapy, the skin eruption disappeared, but the size of the enlarged lymph nodes was not changed.

In July 2010, follow-up chest CT demonstrated increased size of lymph nodes at the right pulmonary hilar region and mediastinum (Fig. 3B). Furthermore, concentration of sIL$2 \mathrm{R}$ was increased $(3,469 \mathrm{U} / \mathrm{mL})$. The patient underwent biopsy of the left supraclavicular lymph node. The nodal architecture was completely obliterated by an infiltration of proliferating histiocytes, lymphocytes, and mononuclear and multinuclear giant cells with prominent nucleoli and abundant cytoplasm (Fig. 4A). These giant cells were determined to have the following phenotype by immunohistochemical ex- 
(A)

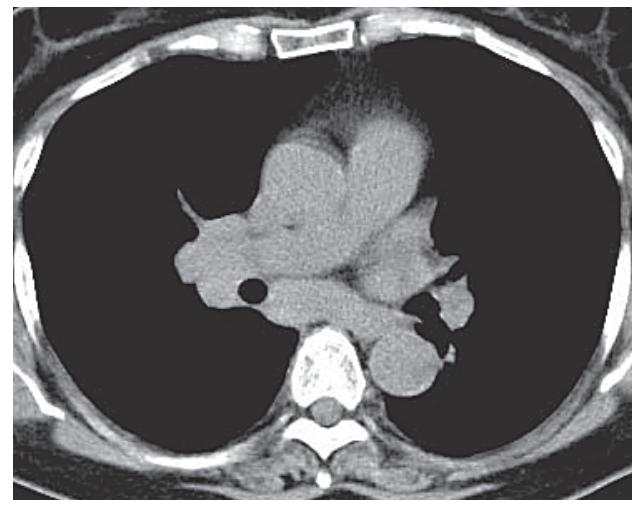

(B)

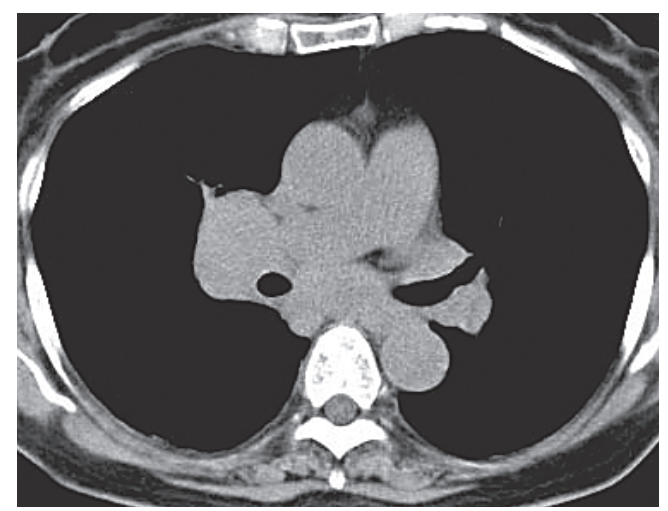

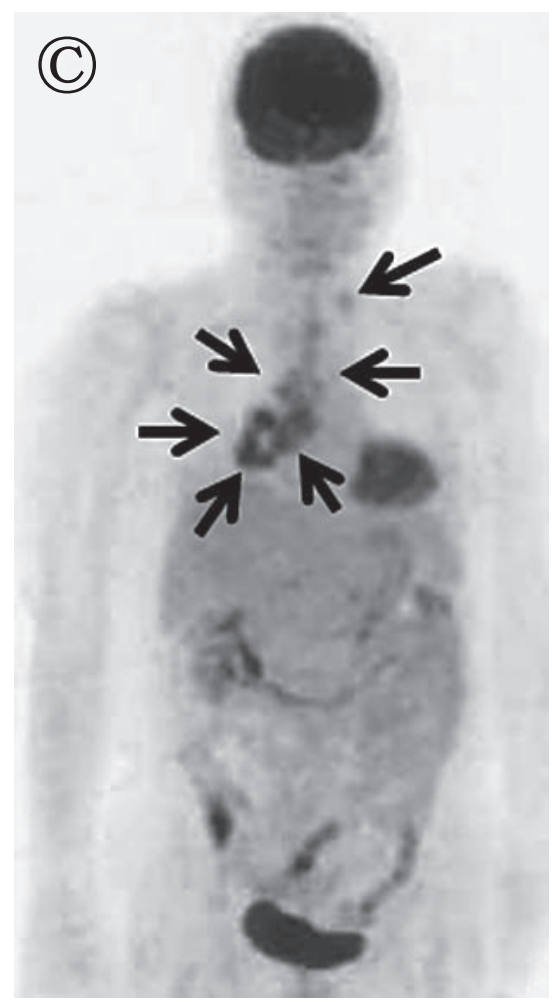

Fig. 3. Computed tomography (CT) scan of the chest $(3 A, 3 B)$. Whole-body 2-[18F]fluoro-2deoxy-D-glucose positron emission tomography combined with computed tomography (FDGPET/CT) (3C). In September 2009, CT scan identified lymph node swelling at the right pulmonary hilar region and mediastinum $(3 A)$. In July 2010, these lymph nodes were increased in size $(3 B)$. Abnormal uptake was detected in pulmonary hilar lymph nodes (arrows), mediastinal lymph nodes (arrows), supraclavicular (arrows), and mesenteric lymph nodes (3C).

amination : $\mathrm{CD} 20^{-}, \mathrm{CD}^{-}, \mathrm{CD}^{-}, \mathrm{CD}^{-}, \mathrm{CD} 15^{+}$(Fig. 4B), $\mathrm{CD}^{+} 0^{+}$(Fig. 4C), $\mathrm{PAX}^{+}$(data not shown). They were considered to be Hodgkin's cells and Reed-Sternberg cells. Thus, a diagnosis of mixed cellularity classical Hodgkin's lymphoma was made. The background cells were predominantly mature-looking small lymphocytes with little cyto- plasm and minimal nuclear abnormalities. Immunohistochemistry revealed that these lymphocytes were predominantly positive for CD3 (Fig. 4D), CD8 (Fig. 4F), and TIA-1 (data not shown). Moreover, polymerase chain reaction analysis of the lymph node showed monoclonal rearrangement of the TCR $\gamma$ gene (data not shown). In situ hy- 
Tsuji T, et al.
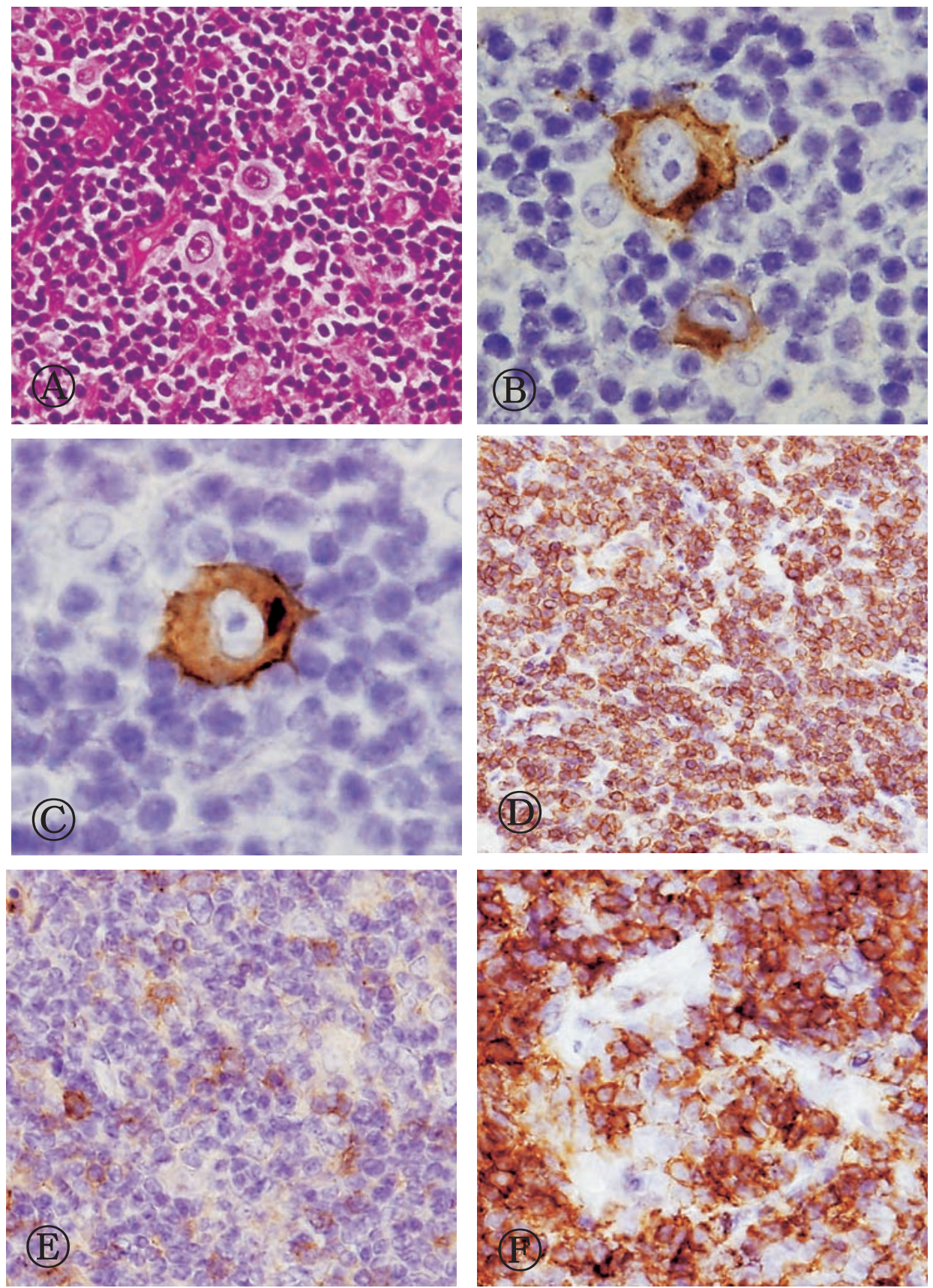

Fig. 4. H\&E stain and immunohistochemical stain of the biopsy sample $(4 A, \mathrm{H} \& \mathrm{E} ; 4 B$, $\mathrm{CD} 15 ; 4 C, \mathrm{CD} 30 ; 4 D, \mathrm{CD} 3 ; 4 E, \mathrm{CD} 4 ; 4 F, \mathrm{CD} 8)$. The nodal architecture was completely obliterated by an infiltration of proliferating histiocytes, lymphocytes, and mononuclear and multinuclear giant cells $(4 A)$. Giant cells were positive for CD15 (4B) and CD30 (4C). The background CD3-positive lymphocytes $(4 D)$ were predominantly positive for CD8 $(4 F)$ in comparison with CD4 (4E). 
bridization for Epstein-Barr virus (EBV)-encoded RNA was negative. The number of EBV DNA copies in the serum was under $2.0 \times 10^{2}$ copies $/ \mathrm{mL}$ (normal, $<2.0 \times 10^{2}$ copies $/ \mathrm{mL}$ ). $\mathrm{ABVd}$ (doxorubicin, bleomycin, vinblastine, and dacarbazine) regimen was started. After two courses of ABVd therapy, the size of the enlarged lymph nodes markedly decreased.

Fludarabine is known to produce prolonged low $\mathrm{CD}^{+} \mathrm{T}$ lymphocyte counts, and contributes to immunodeficiency status. Immunodeficiency status increases the risk of CHL, and immunodeficiency-related HL is categorized as follows : (1) HL post-transplant lymphoproliferative disorders, (2) HL in HIV/acquired immunodeficiency syndrome, (3) Hodgkin's variant of Richter syndrome in CLL in association with fludarabine, (4) HL in other immunodeficiency states, and (5) Hodgkin-like lymphoid proliferation including senile $\mathrm{EBV}^{+}$ B-cell lymphoproliferative diseases (EBV-BLPDs). ${ }^{5}$ In the patients treated with fludarabine, EBV-BLPD triggered by fludarabine-induced immunodeficiency was described. ${ }^{5}$ Sustained reduction of $\mathrm{CD}^{+}$T-lymphocyte counts impairs anti-viral immunity mediated by $\mathrm{CD} 8^{+}$cytotoxic $\mathrm{T}-$ lymphocytes, which results in host deficiency in controlling the proliferation of EBV-infected B-cells and, ultimately, in the development of EBV-BLPD. ${ }^{7}$ However, the frequency of EBV infection in fludarabine-associated HL is variable, and it is controversial whether EBV alone plays a crucial role in the pathogenesis of fludarabine-associated HL. In the present patient, there was no evidence of EBV activation, and hence her CHL seems not to have been triggered by this virus.

The T-cell infiltrate in CHL predominantly comprises $\mathrm{Th} 2$ and T-regulatory cells, which are positive for CD4, CD25, and CCR4, and generally lacks Th1 cells, $\mathrm{CD} 8^{+}$cytotoxic $\mathrm{T}$ cells, and natural killer cells. ${ }^{8}$ The present case, however, showed an increase of $\mathrm{CD} 8^{+}$cytotoxic T-cells. Moreover, these cells showed a clonal TCR $\gamma$ gene rearrangement. We considered this case as fludarabine-associated CHL against a background of T-PLL.

In conclusion, HL can occur in T-PLL patients after treatment with fludarabine. Clinicians should recognize the possibility of secondary HL in patients previously treated with fludarabine. Further investigation is necessary to discover the pathogenesis of fludarabine-associated HL.

\section{REFERENCES}

1 WHO Classification of Tumours, Tumours of Haematopoietic and Lymphoid Tissues. Swerdlow SH, Campo E, Harris NL, Jaffe ES, Pileri SA, et al. (eds): 4th ed, Lyon, IARC, 2008

2 Robak T, Robak P: Current treatment options in prolymphocytic leukemia. Med Sci Monit 13:RA69-80, 2007

3 Maeda A, Iwai K, Ishibashi T: Successful treatment of T-cell prolymphocytic leukemia (T-PLL) with fludarabine monophosphate. Rinsho Ketsueki 50:658-662, 2009

4 Wijermans PW, Gerrits WB, Haak HL: Severe immunodeficiency in patients treated with fludarabine monophosphate. Eur J Haematol 50:292-296, 1993

5 Said JW: Immunodeficiency-related Hodgkin lymphoma and its mimics. Adv Anat Pathol 14:189-194, 2007

6 Fong D, Kaiser A, Spizzo G, Gastl G, Tzankov A: Hodgkin's disease variant of Richter's syndrome in chronic lymphocytic leukaemia patients previously treated with fludarabine. Br J Haematol 129:199-205, 2005

7 Abruzzo LV, Rosales CM, Medeiros LJ, Vega F, Luthra R, et al.: Epstein-Barr virus-positive B-cell lymphoproliferative disorders arising in immunodeficient patients previously treated with fludarabine for low-grade B-cell neoplasms. Am J Surg Pathol 26:630636, 2002

8 Mani H, Jaffe ES: Hodgkin lymphoma : an update on its biology with new insights into classification. Clin Lymphoma Myeloma 9:206-216, 2009 